\title{
SIMULATOR OF ROAD TUNNEL
}

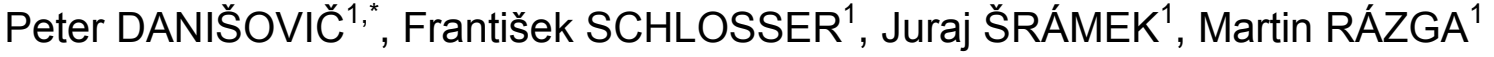 \\ ${ }^{1}$ Department of Construction Management, Faculty of Civil Engineering, University of Žilina, \\ Univerzitná 8215/1, 01026 Žilina. \\ corresponding author: peter.danisovic@fstav.uniza.sk.
}

\section{Abstract}

A Tunnel Traffic \& Operation Simulator is a device of the Centre of Transport Research at the University of Žilina. The Simulator allows managing technological equipment of virtual two-tube highway tunnel, which is interconnected with simulation of vehicle traffic in tunnel. Changes of the traffic-operation states and other equipment are reflecting at the simulated traffic, as well as simulations of various emergency events in traffic initiate changes in tunnel detecting and measuring devices. It is thus possible to simulate emergency states, which can be affected by various faults of technology as well as by climatic conditions. The solutions can be found in irreplaceable experiences of Slovak road tunnel operators, changes of trafficoperation states, visualizations of operator technological display screens, technological devices labelling in order to increase operational safety of road tunnels.
\end{abstract}

\section{Keywords:}

Road tunnel simulator;

Tunnel;

Operator;

Emergency event;

Safety.

\section{Introduction}

The Centre of Transport Research at the University of Žilina has a unique device in the form of the Tunnel Traffic \& Operation Simulator (hereinafter referred to Simulator). The Simulator is part of a project co-founded from the resources of the EU. The aim of the project is to increase operation safety of road tunnels by means of simulations at mentioned device. An essential part of this research is also a close cooperation with the tunnel manager organization of Slovak road tunnels (National Motorway Company) and especially, the data collection from simulations with the participation of the road tunnels operators.

\section{Simulator of Road Tunnel (SRT)}

The Simulator consists of two independent devices and one software:

- central control system (CCS) - the part of remote tunnel equipment control,

- manual control module (MCM) - the part of manual tunnel equipment control,

- EMUT - the software for evidence of tunnel incidents.

Simulator is developed in the terms of functionality point of view on the basis of real control algorithms used for managing of existing tunnels [1]. By simulation of incidents, which are rare in the real tunnel operation, it is possible to check over conception and correctness of managing. Computer visualization of the environment of tunnel managing is the same as at the real operator control centre of twin-tube tunnel. In contrast to real traffic of vehicles, the simulation of videosurveillance displays a virtual traffic of vehicles in tunnel tubes. As most of operator control centres, also the operator control centre of Simulator is realized for two-man operating tunnel personnel operator for tunnel technology management and operator for traffic management. Of course, one operator can control entire tunnel. Recording of process of faults, incidents, responses and interventions of CCS and operators are always carried out. 


\section{Central Control System (CCS)}

The basis for CCS of simulator is a coordinator workstation, in which there is located a simulation module of CCS, and which is superior to other parts, such as simulation of videosurveillance and system of simulator visualization (two operator workstations) (Fig. 1) [2].
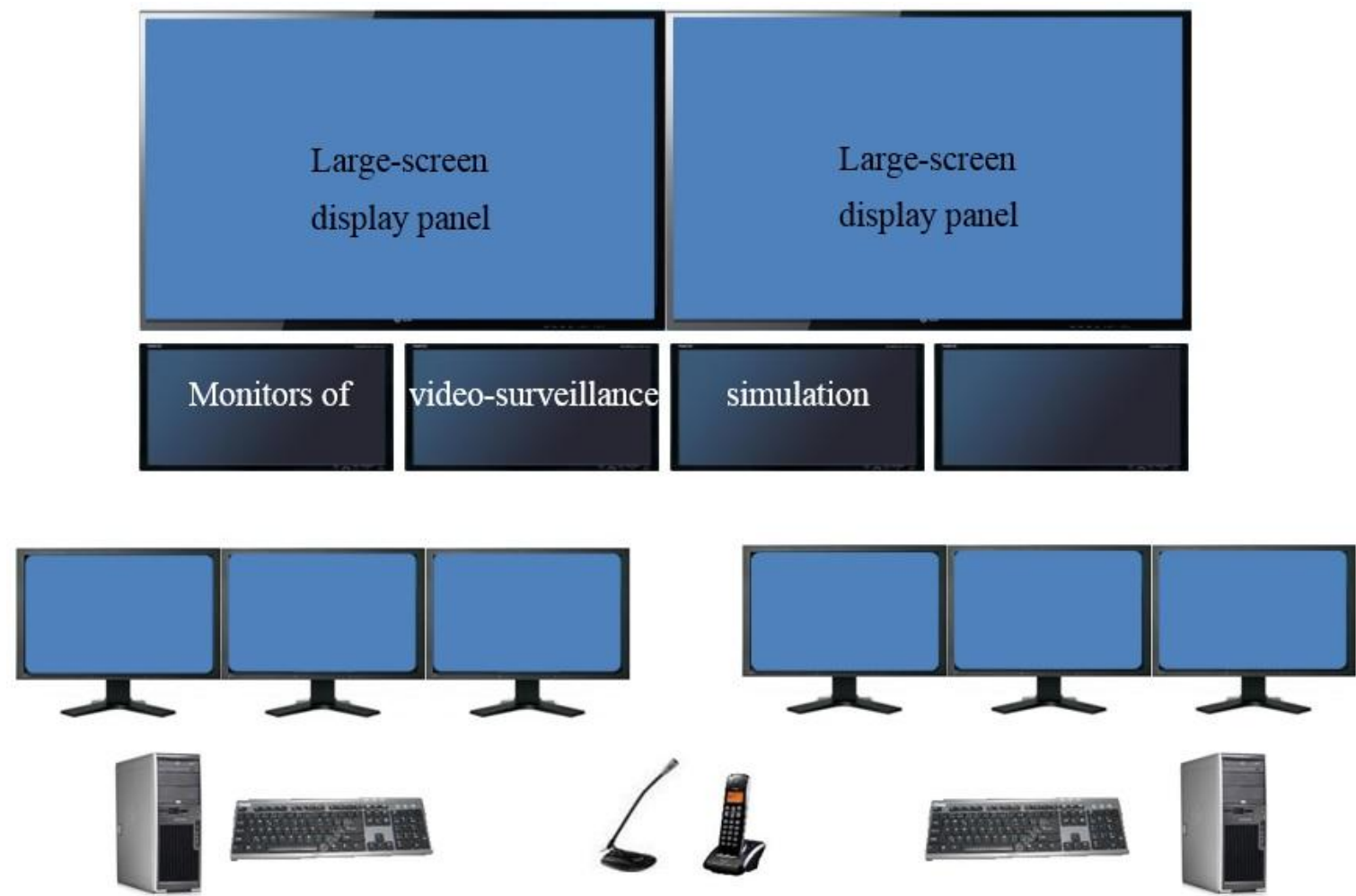

Fig. 1: Scheme of simulator control centre.

The CCS simulates the operation of the twin-tube highway tunnel with a length of about $1000 \mathrm{~m}$ with connection to continuous crossroads. Technological equipment of virtual tunnel is in accordance with the Slovak republic government regulation No. 344/2006 on minimum safety requirements for tunnels in the road network [3], TP 11/2011 Fire safety in road tunnels and TP 12/2011 Road Tunnel Ventilation and more. The device fully respects requirements arising from TP 09/2008 Devices, infrastructure and systems of technological equipment of roads. On the wall of operator workplace SRT (Fig. 2), there we can monitor the status of technological devices and virtual traffic in the tunnel.

Two large LED panels (Fig. 3) show the longitudinal section of tunnel tubes with the visualization of tunnel technological equipment status, such as:

- vehicle counters,

- traffic signs head in tunnel, in front of tunnel tubes and crossroads,

- power sources,

- emergency power supplies,

- ventilation system of tunnel tubes and cross connections,

- lighting of tunnel tubes, tunnel portals and cross connections,

- detecting and measuring devices,

- evacuation guide equipment,

- fire safety equipment,

- others. 


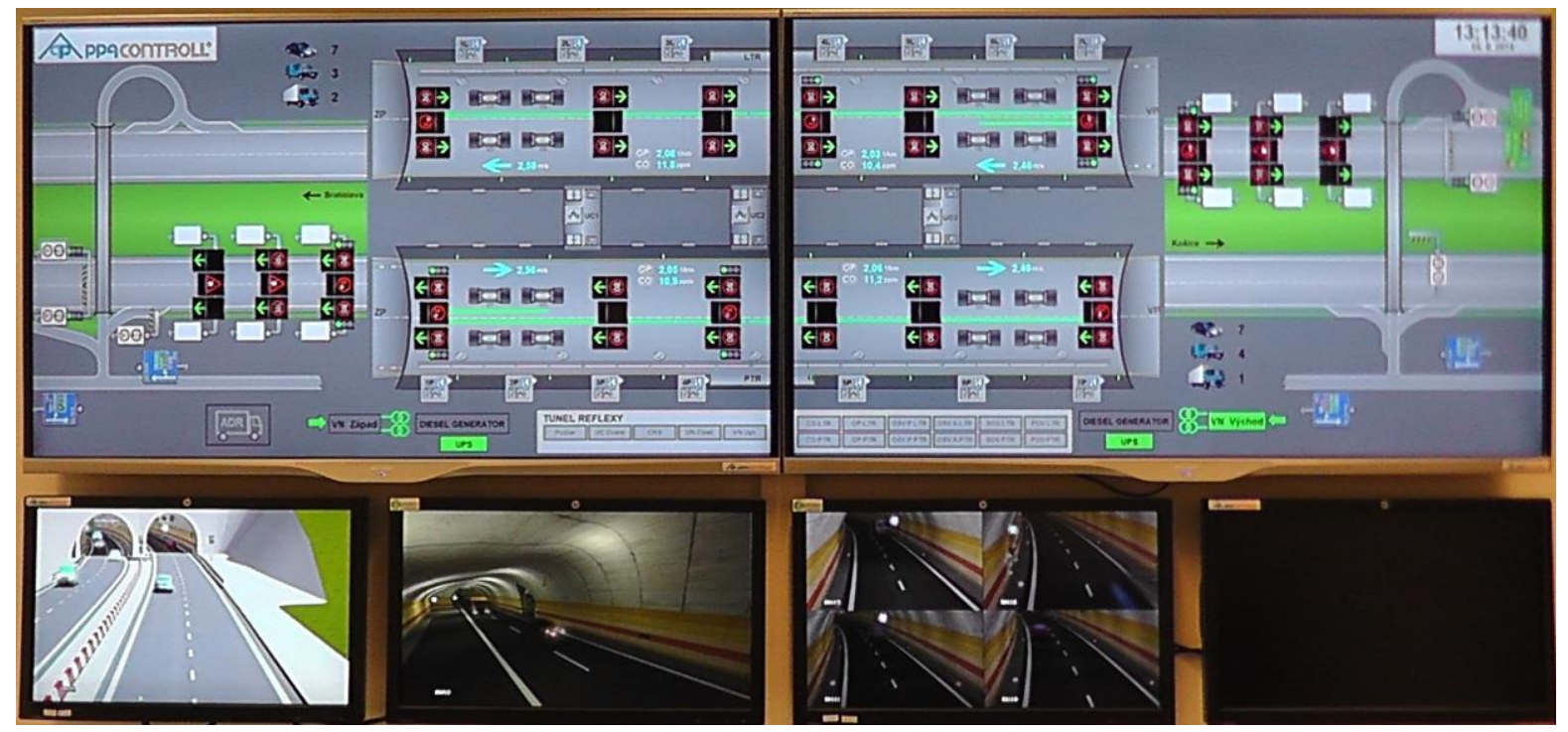

Fig.2: Wall of virtual operator control centre.

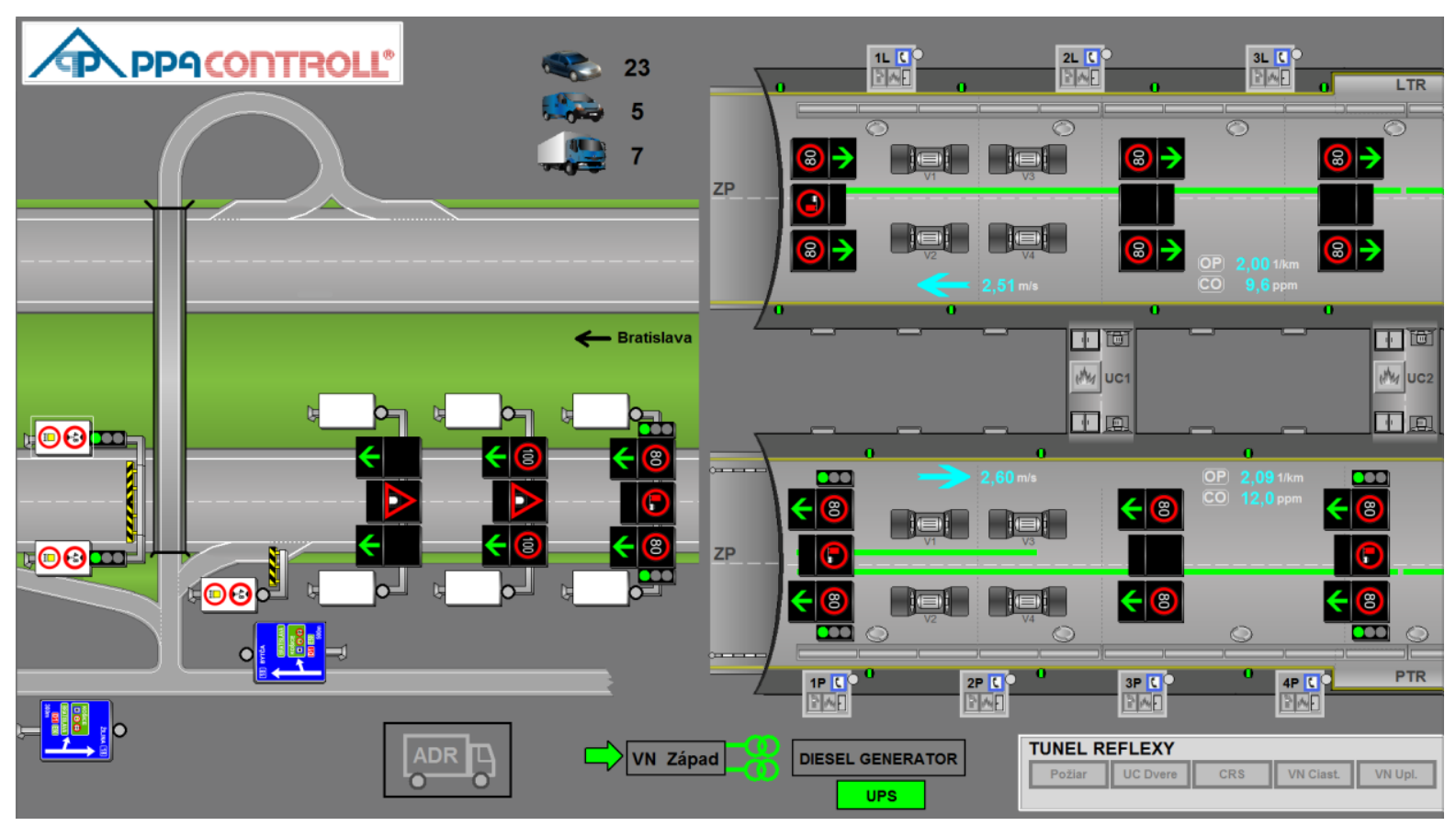

Fig. 3: Detail of LED panel from the wall of operator control centre.

In the bottom of the wall, there are three LCD monitors (Fig. 2) for tunnel traffic surveillance. It is possible to select a view from arbitrary camera of video-surveillance. The third monitor is divided into four parts of which two show views from cameras consecutively for each tunnel tube. The first monitor serves at the same time like an alarm display (Fig. 4). It means that in the case of detected alarm the relevant view of a camera will be displayed on this monitor. Monitor displaying alarm camera is superordinate to selection of cameras by operator. In this manner, it is prevented from detected incident failure up to the moment when is its alarm confirmed (deactivated) by operator. The second monitor is optional and serves to operators for choice of view from arbitrary camera of simulated video-surveillance.

Each operator has three monitors into which he can choose a scheme of up-to seven technological screens covering the spectrum of all technological devices in tunnel needed to keep safe operation: 
- continuous section of traffic management in front of the west portal,

- traffic management in tunnel (Fig. 5),

- ventilation, lighting and measurement of physical dimensions,

- safety,

- west power supply,

- east power supply,

- continuous section of traffic management in front of the east portal.

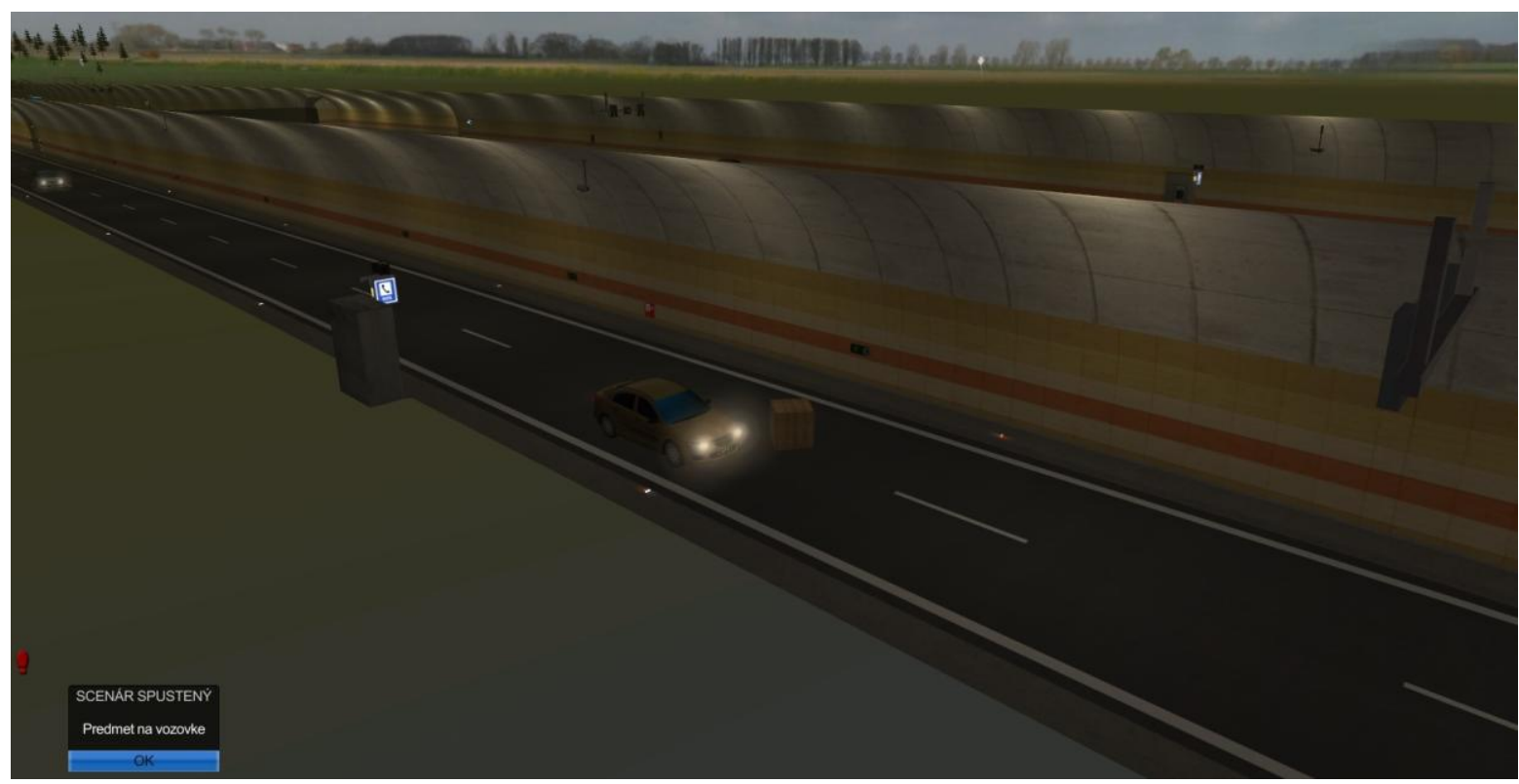

Fig. 4: Simulation of emergency event.

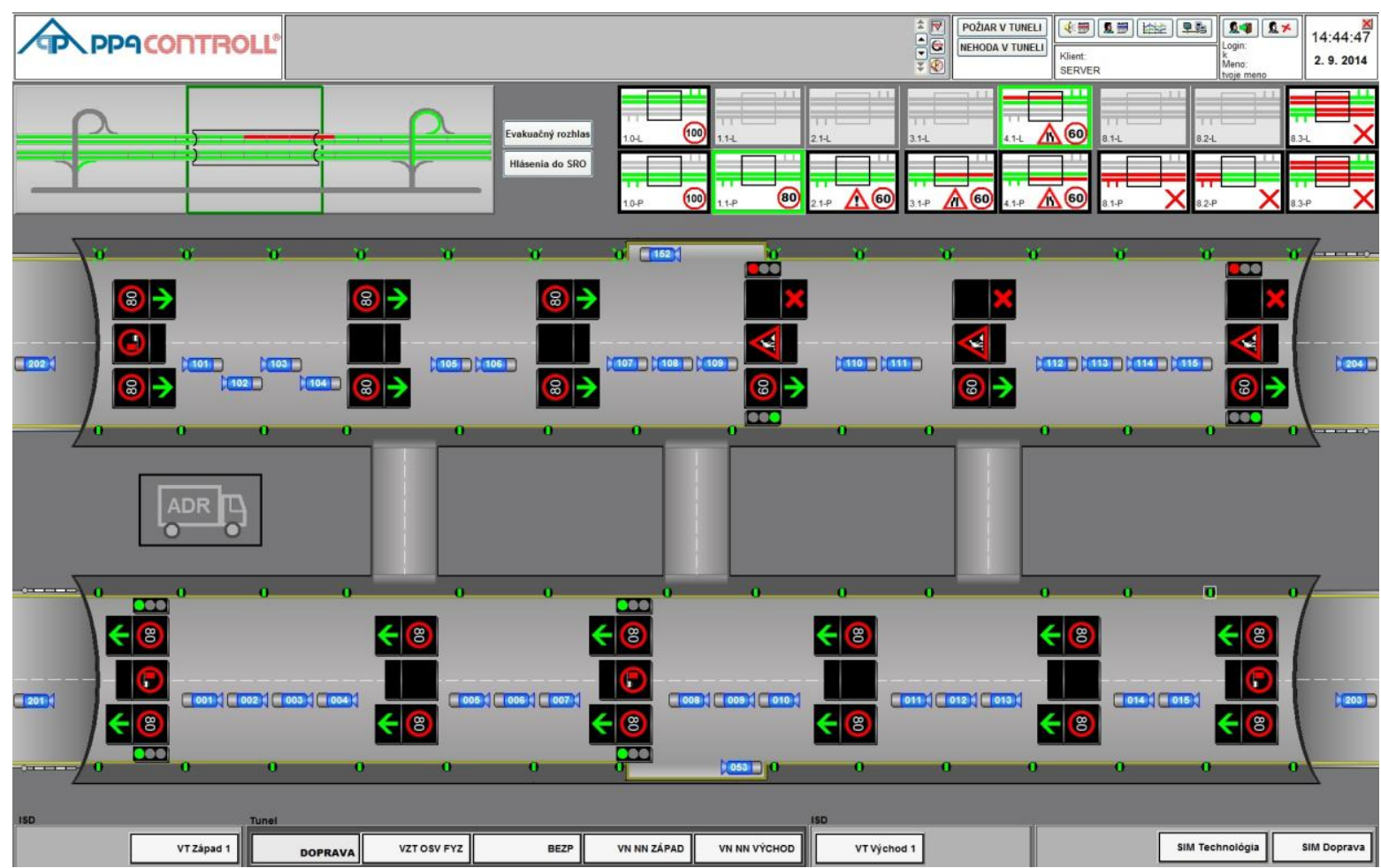

Fig. 5: Operator's technological screen of traffic management in tunnel. 
Visualization and operating interfaces of CCS are complemented by typical elements of equipment of real operator tunnel control centre:

- microphone for simulation of announcements to evacuation broadcasting,

- telephone of internal net for simulation of connection (linked to coordinator's telephone):

- with joint rescue services,

- with emergency stations,

- with tunnel personnel,

- with safety officer [4].

System saves all of the alarms, warnings, automatic changes of CCS, activities of operator and coordinator too. It is also possible to create a videorecording from continuance of emergency event. Videorecordings are requisite component of emergency event assessment in road tunnels.

\section{Manual Control Module (MCM)}

Manual control module (MCM) is autonomous functional device (Fig. 6) that is used by tunnel specialists as an example of hardware solution of automatic process managing road tunnel technological entities. Configuration of MCM system management comes out from real structure of automatic machine which is used for managing of real road tunnels and highways under the administration of National Motorway Company. Configuration consists of simplified versions of familiarly used communication levels and architectures. Their automatic managing of technology by CCS is divided into three main levels:

- directive - net of data collection from input/output interfaces which complete managing PLC automatic machines (Programmable Logic Controller) and ensure functional technology managing,

- procedural - net of communication on the level of managing automatic machines, it ensures transformation of technological device conditions into the electrical form,

- visualization- visualization net determined to ensure connection of human operator with managing technology.

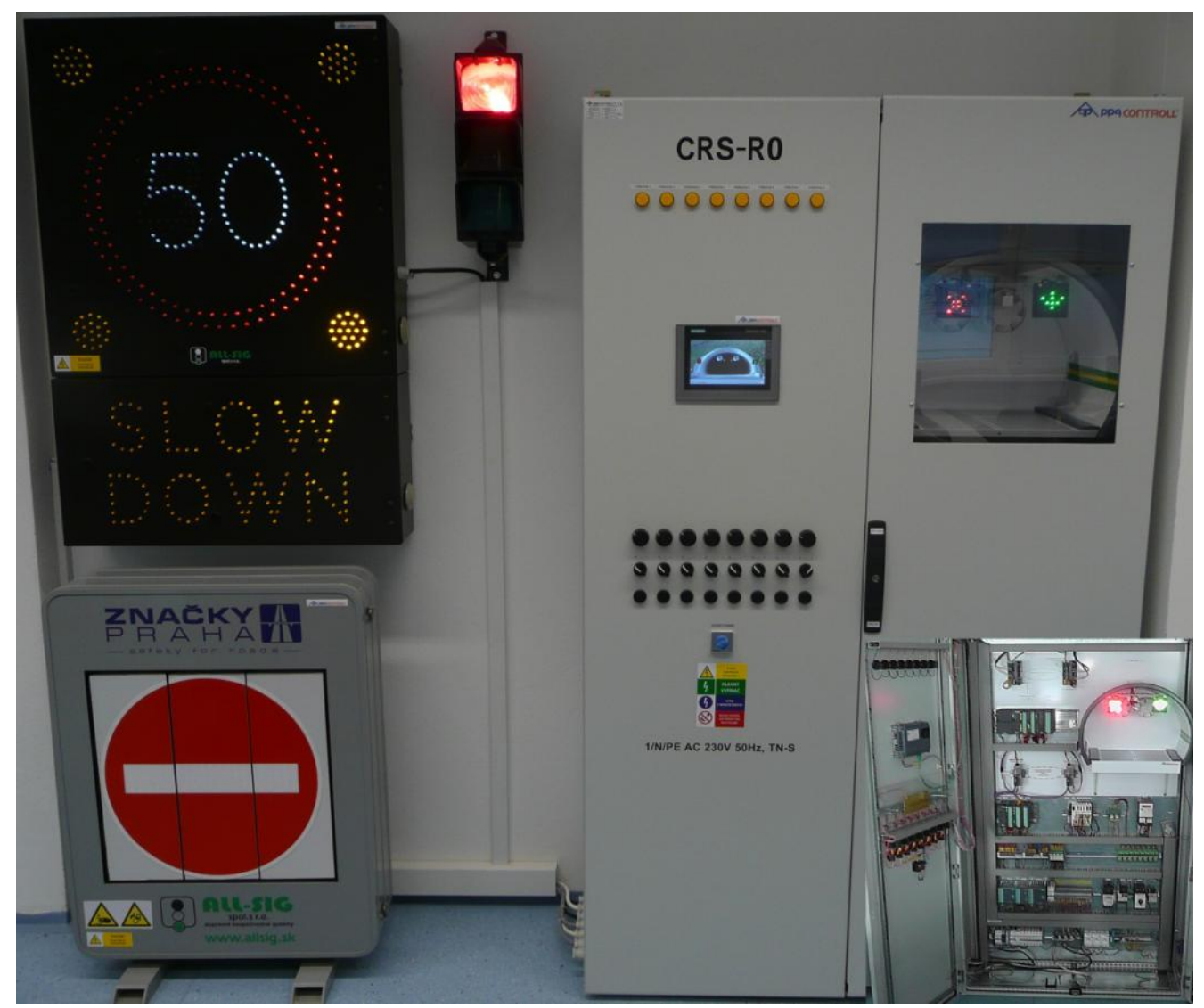

Fig. 6: Manual control module (detail of CCS distributor). 


\section{EMUT}

EMUT is a software which in law TP 02/2014 Safety of road tunnels - Safety documentation allows register significant incidents:

- accidents with personal injury or decease of at least one of participants,

- vehicle fires in tunnel (also in a case when vehicle leaves the tunnel consequently),

- leakages and wastages of dangerous goods [5].

It is necessary to register and asses aforementioned incidents in terms of technical directives. They are part of Safety documentation of every tunnel. Besides those incidents, it is possible to register also all other events which are recorded by tunnel operators at the point of changes of trafficoperation states [6]. EMUT with the filled database allows statistically assess events in accordance with requirements of users for purpose of increasing safety of road tunnel operation.

\section{Conclusions}

Safety of road tunnel users doesn't depend only on design elements of road communication in tunnel, safety and technological level of tunnel equipment but also on tunnel maintenance and last but not least from the skills, knowledge and experiences of operators. Aforementioned circumstances may have great influence on the progress of emergency event, especially on the result from the event participants' point of view. Statistical assessment of database of evidence of tunnel emergency events may identify the events that occur only in specific time and is necessary to focus on them. The results may be in changes of settings of managing technological equipment for purpose of increasing safety of road tunnel operation.

\section{Acknowledgement}

This contribution is the result of the project implementation: "Centre of Transport Research" (ITMS 26220220135) supported by the Research \& development Operational Programme funded by the ERDF.

\section{References}

[1] RÁZGA, M.: Safety in road tunnels. In: CD - Proceedings of International Scientific Conference: Construction Technology and Management CTM 2014, Bratislava (Slovakia), 9-11.9.2014, Edition (C) Slovak University of Technology in Bratislava, ISBN 978-80-227-4243-6, s. 411-416.

[2] RÁZGA, M. - SCHLOSSER, F.: Technical and technological aspects of safety of highway tunnels (in Slovak). In: CD of papers $-16^{\text {th }}$ international conference of postgraduate students Juniorstav 2014, 30.01.2014, Brno, ISBN 978-80-214-4851-3, 5 s.

[3] Slovak republic government regulation No. 344/2006 on minimum safety requirements for tunnels in the road network (in Slovak).

[4] DIRECTIVE 2004/54/EC of the European parliament and of the council of 29 April 2004 on minimum safety requirements for tunnels in the trans-European road network.

[5] TP 02/2014 Safety of road tunnels - Safety documentation. MDVRR SR, August 2013.

[6] SCHLOSSER, F. - DANIŠOVIČ, P. - RÁZGA, M.: Risk Analysis in Road Tunnels. In: XXIII Russian - Polish - Slovak Seminar „Theoretical Foundation of Civil Engineering“, Wroclaw (Szklarska Poreba), Poland, August 25-29, 2014. 